\title{
The four epidemiological stages in the global evolution of inflammatory bowel disease
}

\section{Gilaad G. Kaplan (1) and Joseph W. Windsor(D)}

\begin{abstract}
Inflammatory bowel disease (IBD) is a global disease; its evolution can be stratified into four epidemiological stages: Emergence, Acceleration in Incidence, Compounding Prevalence and Prevalence Equilibrium. In 2020, developing countries are in the Emergence stage, newly industrialized countries are in the Acceleration in Incidence stage, and Western regions are in the Compounding Prevalence stage. Western regions will eventually transition to the Prevalence Equilibrium stage, in which the accelerating prevalence levels off as the IBD population ages and possibly as a result of an unexpected rise in mortality during the COVID-19 pandemic. Mitigating the global burden of IBD will require concerted efforts in disease prevention and health-care delivery innovations that respond to changing demographics of the global IBD population. In this Perspective, we summarize the global epidemiology of IBD and use these data to stratify disease evolution into four epidemiological stages.
\end{abstract}

The journey from a few sporadic cases of inflammatory bowel disease (IBD) to millions of people with IBD is a 250-year path beginning with the industrial revolution ${ }^{1}$. The distribution of IBD was initially thought to be bound by ethnicity and geography - predominantly affecting people of Western European descent ${ }^{2}$. By the end of the twentieth century, these boundaries had been shattered with the disease recorded on every populated continent of the globe $e^{3,4}$. Whereas the incidence of IBD in the Western world increased in the twentieth century, the incidence began to increase in newly industrialized countries at the turn of the twenty-first century ${ }^{4}$.

In 1971, Omran proposed the

Epidemiologic Transition Theory to explain human population growth via predominant drivers of mortality. The pre-industrial society was labelled the Age of Pestilence and Famine, in which populations were limited by epidemic outbreaks, deprivation and wars. The Age of Receding Pandemics reflects a reduction in mortality crises and a greater burden of endemic diseases (for example, malaria and tuberculosis). The final transition proposed by Omran was the Age of Degenerative and Human-Influenced Diseases that arises in industrialized and urbanized societies ${ }^{6}$. Mortality is dominated by non-communicable diseases, the occurrence of which is influenced by environmental pressures such as nutrition and lifestyle behaviours ${ }^{6}$. This final stage is a proposed anthropological explanation for the rise in chronic inflammatory conditions ${ }^{7}$. In a 2018 editorial, Kedia and Ahuja postulated that IBD is an example of Omran's final stage $e^{8}$.

The evolution of IBD occurs within Omran's Degenerative and HumanInfluenced Diseases age and has occurred across three distinct epidemiological stages (FIG. 1): Emergence, Acceleration in Incidence and Compounding Prevalence. Emergence is represented by sporadic case reports of $\mathrm{IBD}^{2}$. Acceleration in Incidence is a tipping point whereby incidence steadily increases over several decades, although prevalence remains low $^{3}$. Compounding Prevalence reflects a steady increase in the population living with IBD, despite stabilization or even a decline in incidence? The transition from one stage in the evolution of IBD to the next is a result of human influence: the factors that contribute to these transitions include industrialization, urbanization and westernization of society ${ }^{10}$.

By combining epidemiological principles with temporal prevalence trends, a fourth stage can be postulated: Prevalence Equilibrium, the countervailing force between the increasing mortality of an ageing IBD population and the incidence of IBD (FIG. 1). Prevalence Equilibrium represents a future epidemiological stage that has yet to materialize but provides the framework for predicting the future global burden of IBD. Understanding the changing epidemiological patterns is critical to provide clues to the pathogenesis of disease and to support health-care systems in addressing the rising global burden.

In this Perspective, we provide evidence of the epidemiological stages of IBD using real-world data from different regions across the globe. We show how postulating a fourth stage in IBD evolution provides a theoretical framework for predicting the future burden of disease. A glossary of relevant terms and new terminology introduced herein is detailed in BOX 1 , and a video abstract and interactive map are available online (see Related links).

\section{Stage one: Emergence of IBD}

In many ways, the evolution of IBD parallels the evolution of biological species; thus, we take a cue from the father of evolution, Charles Darwin, who had a surprising connection to the emergence of IBD himself. On 27 December 1831, Darwin embarked on a 5-year journey from England to the coast of South America, across southern Australia, around the Horn of Africa and back to England. Only 18 months of this journey was on water; the rest of the time, Darwin explored foreign lands and made observations that formed the basis of the theory of evolution. In 1859, his seminal book On The Origin of Species By Means of Natural Selection was published, which revolutionized our understanding of biology ${ }^{11}$. Throughout his adult life, Darwin was plagued - even while writing his most famous book - with undiagnosed, chronic, gastrointestinal symptoms (for example, abdominal pain, vomiting, ulcerations in the mouth, eczema and peripheral 


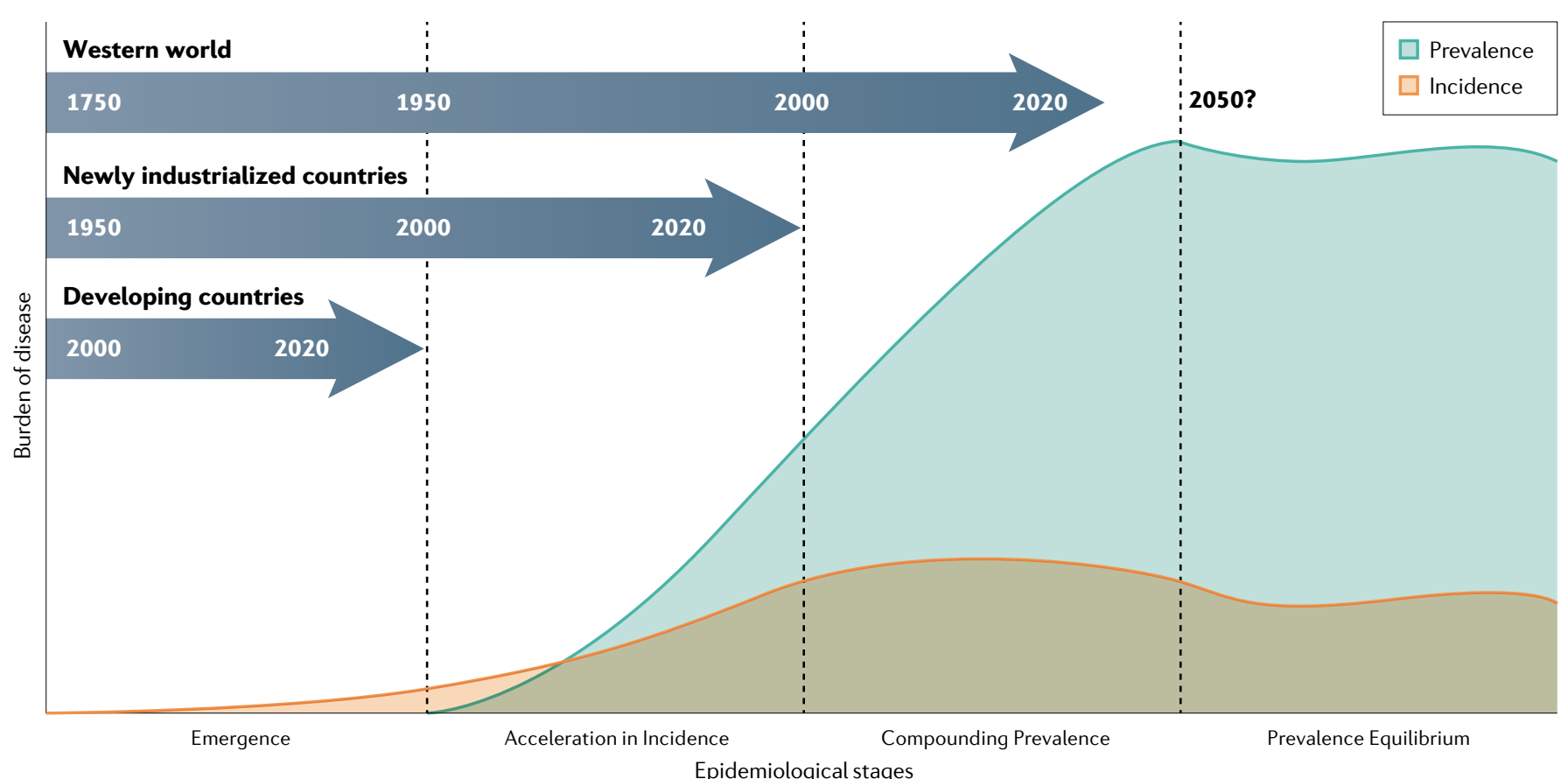

Fig. 1 | Four epidemiological stages of IBD evolution. The changing pattern in the incidence (orange) and prevalence (blue) of inflammatory bowel disease (IBD) across the four the stages of IBD evolution. Developing countries are in the Emergence stage, during which sporadic cases of IBD are documented. Newly industrialized countries are in the Acceleration in Incidence stage, during which incidence rises and prevalence is relatively low. Countries of the Western world are in the stage of Compounding Prevalence, during which incidence is stable, but prevalence is rising steeply. The slope of the prevalence increase will level off with the transition to the Prevalence Equilibrium stage, which represents the opposing force between an ageing IBD population and the incidence of IBD.

neuropathy $)^{12}$. Initially, it was believed that he had contracted Chagas disease in South America, but this has been challenged on the basis that he experienced coexisting eye and skin inflammation suggestive of an underlying diagnosis of Crohn's disease - a diagnosis that was unheard of during Darwin's lifetime (1809-1882) ${ }^{12}$.

The first stage in the evolution of IBD Emergence - occurred in North America and Western Europe following the advent of the industrial revolution. James Watt modified the steam engine in 1764 , which triggered the industrial revolution that led to fundamental societal shifts involving manufacturing, urbanization, agriculture and transportation. In this milieu, IBD emerged in the Western world, starting as a handful of case studies published at the end of the eighteenth century to taking root as a new affliction of health ${ }^{2}$. Matthew Baillie, in his 1793 publication Morbid Anatomy of Some of the Most Important Parts of the Human Body, reported among the earliest cases consistent with a diagnosis of IBD ${ }^{13}$. In 1828, John Abercrombie published a book describing digestive diseases that included patients who, retrospectively, seem to have had IBD as evidenced by ileocaecal disease $^{14}$. However, the first published case that specifically denotes a unique, non-infectious, gastrointestinal disease was in 1859 by British physician Samuel Wilks - the same year that Darwin published his book while possibly affected by the yet-unrecognized Crohn's disease ${ }^{15}$. On the heels of Wilks's classification, several case reports were published in Europe and the USA, including a case series from William Hale White in 1888 that introduced the term ulcerative colitis into the medical lexicon ${ }^{16}$. With the formal naming of ulcerative colitis, the Western world became rooted in the first stage of IBD evolution ${ }^{17}$.

By the early 1900s, awareness of ulcerative colitis was mounting with the transition from sporadic case reports to regularly recognizable diagnoses. In 1909, the Royal Society of Medicine assembled a symposium in London, England, to address the surge in the number of cases of ulcerative colitis. The physicians at the symposium reviewed the 317 documented cases of ulcerative colitis that had been collected from seven London hospitals (Guy's, London, St Mary's, St Thomas', St Bartholomew's, St George's and Westminster) over the preceding 20 years (1888-1907). In the first collaborative effort to investigate the disease, the physicians documented that two or three patients with ulcerative colitis were admitted per annum at each hospital ${ }^{18}$.
Awareness of ulcerative colitis expanded during the early twentieth century; additionally, an inflammatory disorder outside the colon was beginning to be recognized. Wilks's original case report in 1859 (later understood to be a case of Crohn's disease) described ileal inflammation ${ }^{15}$. T. Kennedy Dalziel reported a surgical case series in 1913 that described chronic inflammation of the terminal ileum ${ }^{19}$. Finally, the landmark 1932 paper by Crohn et al. on regional ileitis fundamentally entrenched two distinct gastrointestinal chronic inflammatory diseases under the paradigm of IBD and established Crohn's disease as clinically distinct from ulcerative colitis $^{20}$. By the 1950s, ulcerative colitis and Crohn's disease were established in the Western world, which was then in the process of shifting to the second epidemiological stage in the evolution of IBD.

By contrast, recognition of IBD in the first half of the twentieth century in developing countries of the time lagged behind that in the Western world, though Chopra and Ray described 120 cases of ulcerative colitis in Kolkata, India, in 1939 (REF. ${ }^{21}$ ). The emergence of IBD in Asia and Latin America occurred later in the twentieth century. For example, the first reported case of ulcerative colitis in the medical literature in China 
was reported in $1956\left(\mathrm{REF}^{22}\right)$ - a century after Darwin's publication of the theory of evolution and Wilks's first published case report in England ${ }^{2}$.

\section{Stage two: Acceleration in Incidence}

In 2000, Crutzen and Stoermer postulated that the effect of human activity on the Earth's ecosystem had shifted the planet's geological timescale ${ }^{23}$ : they named this period the Anthropocene ${ }^{24}$. The Anthropocene began with the industrial revolution, coinciding with the emergence of IBD in the Western world. During the Anthropocene, human population growth has increased tremendously. Temporal trend analyses detected an inflexion point after World War II, confirming an exponential increase in the global population not observed during any preceding period in human history ${ }^{25}$. The global human population doubled, from three billion in 1960 to six billion in $1999\left(\mathrm{REFS}^{25,26}\right)$. The dramatic rise in the population since 1950 was termed the 'great acceleration'25,27. The great acceleration is attributed to multiple factors including technological advances, improvements in health care and hygiene, energy utilization, transportation, agriculture and diet, urbanization and the interconnectivity of global economies and societies $^{27}$.

In parallel to the great acceleration in human population, the Western world transitioned to the second epidemiological stage in the evolution of IBD: the (Great) Acceleration in Incidence. The components of the second epidemiological stage include exponentially increasing incidence in conjunction with low prevalence. In the Western world, numerous population-based epidemiological studies show that the Acceleration in Incidence of IBD spanned the second half of the twentieth century ${ }^{3}$. The majority of population-based studies evaluating inception cohorts from the 1950s to the 1990s showed steadily increasing incidence for both ulcerative colitis and

\section{Box $1 \mid$ Glossary of terms}

- Ceiling Incidence Range ${ }^{\text {a }}$ : the range of maximal reported incidence values as defined by the 90th to 100th percentiles of the amalgamated incidence data reported in a region.

- Coalescing Incidence Range ${ }^{\text {a }}$ : the range of reported incidence values as defined by the 25 th to 75 th percentiles (the interquartile range) of the amalgamated incidence data reported in a region.

- Developing countries: countries/regions categorized as Least Developed by the United Nations (2019 definitions) ${ }^{99}$.

- Epidemiologic Transition Theory: a theory of epidemiological epochs defined by population growth rates and predominant drivers of mortality.

- EWAR-IBDa: the elderly to working age ratio (EWAR); the ratio of the prevalence of inflammatory bowel disease (IBD) among older people to the prevalence among the working-age population, where the older population is defined as those aged $>64$ years and the working-age population is defined as those aged $15-64$ years.

- Newly industrialized countries: countries/territories categorized as Economies in Transition or Developing Economies by the United Nations (2019 definitions) ${ }^{99}$.

- Prevalence Doubling Period ${ }^{a}$ : the time taken for the prevalence in a defined region to double.

- Stage 1: Emergence ${ }^{a}$ : the first stage of IBD evolution, in which sporadic incident cases begin to emerge in a population.

- Stage 2: Acceleration in Incidence ${ }^{\text {a }}$ the second stage of IBD evolution, in which a dramatic increase in the number of incident cases is observed, but overall prevalence remains low.

- Stage 3: Compounding Prevalence ${ }^{a}$ : the third stage of IBD evolution, in which incidence rates stabilize or even decline, but the slope of prevalence continues to accelerate owing to decades of high incidence with low mortality.

- Stage 4: Prevalence Equilibriuma: the theoretical fourth stage of IBD evolution, in which the slope of prevalence begins to level off owing to stable incidence and an ageing prevalent population with higher mortality.

- True Rise of Incidence ${ }^{\text {a }}$ an increase in the incidence of disease as a result of exposure to environmental determinants.

- Unmasking of Incidence ${ }^{a}$ : an increase in the incidence of disease due to economic factors that improve awareness and detection of persons contracting the disease.

- Western world: countries/territories from Western Europe and regions that were predominantly colonized by Europeans (that is, North America and Australia) that share cultural, lifestyle, dietary and socioeconomic influences in their society (Developed Economies as classified by the United Nations (2019 definitions) $)^{99}$.

andicates a new term used in this Perspective.

Crohn's disease $e^{3}$. Meticulous longitudinal studies clearly documented this steady increase in incidence of $\mathrm{IBD}^{28,29}$. For example, a study of the incidence of Crohn's disease in Cardiff, Wales, is the longest continuous epidemiological analysis of the incidence of Crohn's disease that dates back to the original description of regional ileitis in $1932\left(\mathrm{REF}^{29}\right)$. Initially, the incidence was low and flat ( 0.27 and 0.09 per 100,000 in 1933 and 1943, respectively), but showed a spike towards the 1980 s (0.98 per 100,000 in $1953,2.4$ per 100,000 in $1963,5.2$ per 100,000 in 1973 and 9.1 per 100,000 in 1983). Thereafter, the incidence stabilized (6.0 per 100,000 in 1993 and 7.0 per 100,000 in 2003 $)^{29-31}$. Similarly, a longitudinal cohort study of ulcerative colitis in Olmsted County, $\mathrm{MN}, \mathrm{USA}$, showed a rise in incidence from 0.6 per 100,000 (1940-43), to 4.0 per 100,000 (1944-53), 6.4 per 100,000 (1954-63), 9.3 per 100,000 (1964-1973), 10.2 per 100,000 (1980-89 and 1990-99) and to 12.2 per $100,000(2000-2010)^{28,32}$. Similar findings have consistently been reported throughout countries/regions in the Western world; for example, the incidence of Crohn's disease and ulcerative colitis increased by $4.9 \%$ and $4.0 \%$ per year, respectively, in Denmark from 1978 to $2002\left(\right.$ REF. $\left.^{33}\right)$, by $4.5 \%$ and $5.0 \%$ per year, respectively, in Iceland from 1950 to $1970\left(\right.$ REF. $\left.^{34}\right)$, and by $11.1 \%$ and $8.9 \%$ per year, respectively, in Hungary from 1977 to 2001 (REF. $^{35}$ ).

A systematic review of population-based studies investigating the incidence of IBD from 1990 to 2015 revealed a shifting paradigm of stabilizing incidence in the Western world ${ }^{4}$. In many regions in the Western world, the rapidly increasing incidence of IBD levelled off in the last decades of the twentieth century and, in some regions, reduced at the turn of the twenty-first century. For example, the most recent data from Canada suggest that incidence is stable, but varies according to region: incidence is stable in Alberta, decreasing in Manitoba, Nova Scotia and Quebec, and variable in Ontario by age group (increasing in children and adults aged 30-60 years, but stable among other age groups) ${ }^{36,37}$. Since 1990, more than three-quarters of studies reported stable or decreasing incidence of IBD in the Western world ${ }^{4}$. Most of these studies report incidence across all ages, though the decline in incidence of IBD might be driven by adult-onset IBD. By contrast, some studies have found that IBD incidence in children ${ }^{38}$, including IBD of very early onset $^{39}$, has increased in the Western world over the past two decades. Furthermore, 
incidence continues to increase in certain countries including New Zealand ${ }^{40}$ and some countries/regions in Europe, such as Spain $^{41}$ and Denmark ${ }^{42}$. Even among the countries/regions with increasing incidence, the collective data indicate that this might be particular to Western nations catching up to a common incidence. For example, in southern Spain, the incidence of IBD increased from 3.5 per 100,000 in 1995-2000 to 14.7 per 100,000 in $2001-2014$, which is still lower than most reported incidence values in the Western world, for which the mean incidence for the period 2001-2014 was 1.4 times higher $(19.77 \text { per } 100,000)^{41}$. Future studies will demonstrate whether incidence will eventually level off in most countries/regions in the Western world; such stabilization in incidence will denote the end of the second epidemiological stage.

Demarcating the end of the second epidemiological stage is fundamentally important because it enables the calculation of the Coalescing Incidence Range and the Ceiling Incidence Range. The Coalescing Incidence Range is the range of incidence values reported in most regions within a unit of time. Ng et al. performed a systematic review of incidence values between 1990 and 2015, which provides our current understanding of the Coalescing Incidence Range and Ceiling Incidence Range for the Western world ${ }^{4}$. FIGURE 2 displays the Coalescing Incidence Range as defined by the interquartile range. Since 2000 (that is, the end of the second stage within the Western world), the Coalescing Incidence Ranges of Crohn's disease and ulcerative colitis were 6-11 per 100,000 and 6-15 per 100,000 , respectively (12-26 per 100,000 collectively) in the Western world (FIG. 2). As the year following diagnosis of IBD is often the most costly and resource intensive, the Coalescing Incidence Range is relevant for health administrators and policy makers attempting to define the burden of IBD in patients with newly diagnosed disease as compared with the burden in the prevalent population as a whole.

Additionally, the systematic review data of $\mathrm{Ng}$ et al. provide the Ceiling Incidence Range for the Western world, which is the range of maximal reported incidence values as defined by the 90th to 100th percentiles. For Crohn's disease, the Ceiling Incidence Range is in the range $23.8-29.3$ per 100,000 $\left(\mathrm{REFS}^{4,40,43}\right)$, and for ulcerative colitis, it is in the range $23.1-57.9$ per $100,000\left(\mathrm{REFS}^{4,43,44}\right)$. The Ceiling Incidence Range needs to be interpreted cautiously because outliers can represent unique clinical scenarios or methodological biases that skew the incidence range upwards. For example, Nova Scotia, Canada, has been reported to have among the highest incidences of IBD in the world at 55 per 100,000 , which is nearly double the values reported for other provinces in Canada ${ }^{43}$. The high incidence of IBD in Nova Scotia might be methodological in origin because incidence calculations relied on administrative databases using non-validated coding algorithms, which are subject to misclassification biases that might have inflated the incidence ${ }^{45}$. By contrast, the Danish territory of the Faroe Islands had the highest worldwide average annual incidence of IBD at 84.2 per 100,000 in 2011, with a predominance of ulcerative colitis ${ }^{44}$. The investigators articulated an elegant argument that the increased incidence of IBD in the Faroe Islands is not simply an artefact of improved awareness, diagnosis and data capture $^{44}$. Instead, the exceedingly high incidence of ulcerative colitis was explained by a genetic shift in a stable, geographically enclosed society in conjunction with unique environmental exposures within the population ${ }^{46}$.

As most countries in the Western world transitioned into the third stage in the evolution of IBD at the end of the twentieth century, newly industrialized countries in Asia and Latin America entered the second stage: the Acceleration in Incidence. This stage is associated with rapidly rising incidence and low prevalence. For example, the annual incidence of IBD in Bahrain increased from an average of 3 per 100,000 to 12 per 100,000 during the period 1984-2014, but the total prevalent population remained under 200 persons at 26 per $100,000(0.026 \%)\left(\right.$ REF. $\left.^{47}\right)$. Also, a four-decade analysis of the incidence of IBD in Malaysia showed a slow increase from the 1980 s $(0.36$ per 100,000$)$, to the 1990 s $(0.48$ per 100,000$)$ and to the 2000 s $(0.63$ per 100,000$)$, and then more than doubling to 1.46 per 100,000 in the past decade (2010-2018); however, the prevalence of IBD in Malaysia remained low at 23 per $100,000(0.023 \%)$ in $2018\left(\right.$ REF. $\left.^{48}\right)$. Moreover, a systematic review of clinical and epidemiological studies on IBD from Latin America documented the emergence of IBD in the twentieth century with a rapidly rising incidence during the twenty-first century ${ }^{49}$. Similarly, prevalence remains low in most regions in Latin America. For example, in the state of São Paulo, Brazil, the incidence of IBD was 1.0 per 100,000 during the period 1986-1990 $\left(\right.$ REF. $\left.^{50}\right)$ and peaked at 13.3 per 100,000 during the period 2012-2015, but the prevalence remained low at 22.6 per $100,000(2001-2005)^{51}$.

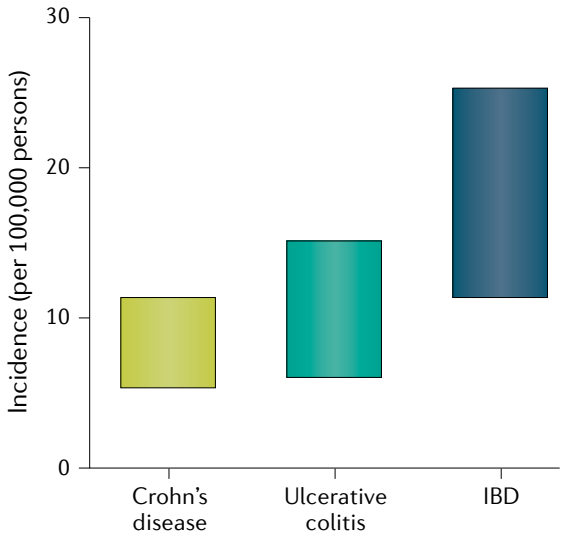

Fig. 2 | Coalescing Incidence Ranges for IBD in regions in the Western world. The Coalescing Incidence Range is the range of average reported incidence values as defined by the range between the 25th and 75th percentiles (interquartile range) of the amalgamated incidence data reported in a region. The boxes show the interquartile ranges of incidence rates reported for Western regions (data drawn from the 2017 systematic review by $\mathrm{Ng}$ et al. ${ }^{4}$ ) for Crohn's disease, ulcerative colitis and all inflammatory bowel diseases (IBD).

Tremendous heterogeneity between the reported incidence rates exists among newly industrialized countries as well as among regions within these countries. For example, in the inception cohort (2011-2013) followed in the Asia-Pacific Crohn's and Colitis Epidemiology Study (ACCESS) ${ }^{52,53}$, the incidence of IBD (2011-2013) was a low 0.43 per 100,000 in the Philippines as compared with 2.98 per 100,000 in Hong Kong $^{53}$. Furthermore, within nine separate regions in mainland China, the incidence varied from 0.54 per 100,000 in Xian to 3.64 per 100,000 in Guangzhou ${ }^{53}$. In part, the explanation for this heterogeneity is the challenge of conducting high-quality population-based chronic disease surveillance research in newly industrialized countries, due to the differences between regional populations (for example, the degree of westernization of diets and lifestyles) that make it difficult to generalize findings ${ }^{45,52,53}$. However, the data available suggest that the rising incidence of IBD and the heterogeneity of reported values in newly industrialized countries at the turn of the twenty-first century can be explained by two fundamental factors: first, the Unmasking of Incidence in which economic advances improve awareness of IBD and access to health care, which reveals undiagnosed IBD; and, second, the True Rise of Incidence due to westernization of society that genuinely increases the number of people being diagnosed with IBD. The Unmasking of 
Incidence is essentially a diagnostic bias: more new cases of IBD are diagnosed as the ability to detect IBD improves. This factor is influenced by economic factors, leading to increased awareness, improved diagnosis, greater access to health care and improved disease surveillance ${ }^{1}$. Collectively, these factors reveal the incidence of IBD and, over time, the reported incidence steadily increases.

An analogy to the Unmasking of Incidence is the ratio of the number of ulcerative colitis diagnoses to the number of Crohn's disease diagnoses in a region. Historically, IBD typically emerges in a population as cases of ulcerative colitis, eventually followed by cases of Crohn's disease. Over time, Crohn's disease becomes more commonly diagnosed as the incidence approximates and, in some cases, surpasses that of ulcerative colitis ${ }^{49}$. For example, in Malaysia the ulcerative colitis to Crohn's disease ratio was 5:1 in the 1980s and fell to $1.7: 1$ from 2010 to $2018\left(\mathrm{REF}^{48}\right)$. The diagnosis of IBD is skewed towards ulcerative colitis in lower income regions with limited technology (for example, access only to sigmoidoscopy); however, as economies improve, so too does health-care infrastructure (for example, access to specialists and colonoscopy), which improves the ability of physicians to accurately diagnose Crohn's disease ${ }^{49}$.

Moreover, newly industrialized countries in Asia and Latin America are experiencing a rising incidence of IBD that is independent of the unmasking phenomenon. The True Rise in incidence is fundamentally an epidemiological transition state whereby individuals carrying genetic susceptibility mutations are exposed to environmental factors associated with the westernization of society that might alter their intestinal microbiota, particularly early in life, which could trigger IBD later in life ${ }^{10}$. Several reviews have contrasted the environmental determinants of IBD in the Western world with those of newly industrialized countries $^{10,54,55}$. Overall, a pattern is observed such that the highest incidence of IBD has been reported in regions with the highest population density ${ }^{10}$. For example, over the past 30 years, China experienced a massive population shift from rural communities to megacities, each with a population of more than ten million ${ }^{53}$. Inhabitants in these urban environments have been exposed to westernization of their society including diets containing higher levels of fat and refined sugars and changes in lifestyle behaviours, such as an increase in smoking, less breastfeeding, greater exposure to antibiotics and improved hygiene and sanitation ${ }^{56}$. All these factors have introduced a pressure that is driving the true incidence of IBD upwards.

Newly industrialized countries in Asia and Latin America are entrenched in the second stage of IBD evolution. Preliminary data suggest that, over the next decade, the incidence in these regions is likely to approximate that in the Western world. For example, some regions in Brazil, China and India already have published incidence values that are close to the Coalescing Incidence Range (for example, 6-11 per 100,000 for ulcerative colitis) in the Western world $^{4,49,53,57}$. Most importantly, with decades of rising incidence, these countries will witness an exponential growth in prevalence until they eventually transition into the third epidemiological stage in the evolution of IBD: Compounding Prevalence.

\section{Stage three: Compounding Prevalence}

In 1980, a seminal paper by Freeman and Hutchison was published in the American Journal of Epidemiology, demonstrating that, in a stable population, prevalence is the product of the incidence and the average duration of disease ${ }^{58}$. This concept was initially applied to acute, self-limited conditions (that is, infectious diseases). The formula also estimates the prevalence of chronic diseases in an ageing population in which disease duration is relatively short owing to high mortality (for example, chronic obstructive pulmonary disease, dementia $)^{59,60}$ or owing to recovery within a specified time period (for example, within a 5 -year window, patients with certain cancers either die or are classified as survivors) ${ }^{61,62}$. Consequently, health-care providers and administrators can integrate information on incidence and disease duration to predict the burden of acute and chronic diseases. However, this formula cannot explain prevalence patterns observed in populations with IBD. Although IBD can occur in individuals of any age, it is most commonly diagnosed in adolescents and young adults (ages 18-35 years) ${ }^{3}$. Without a cure, and owing to relatively low mortality, patients with IBD diagnosed at a young age can live a long life ${ }^{63}$. Consequently, estimating average disease duration over the course of a lifetime is not feasible in IBD; that is, the prevalence of IBD cannot be estimated by multiplying incidence by average disease duration.

Fewer than $20 \%$ of the prevalent population of patients with IBD living in the Western world were over the age of 65 years in $2010\left(\right.$ REF. $\left.^{64}\right)$. With a life expectancy of $\sim 80$ years in the Western world, most patients living with IBD in 2010 are alive today in 2020. In other words, most patients with IBD cared for in a gastroenterology clinic in 2010 are also being cared for now, in 2020. Even if the incidence of IBD in the Western world stabilizes, or declines, new diagnoses of IBD continue to increase the prevalent population of patients with $\mathrm{IBD}^{65}$. Moreover, immigration from low-incidence countries/ regions (for example, developing countries) to the Western world will lead to a further increase in prevalence as the first-generation offspring of immigrants have a similar risk of acquiring IBD as individuals in Western populations ${ }^{66}$. In a chronic, incurable disease of the young, as long as incidence surpasses mortality (that is, there are more patients with newly diagnosed IBD than patients with IBD dying) then prevalence will steadily rise - a phenomenon called 'Compounding Prevalence'1 (FIG. 3).

During the second half of the twentieth century, incidence rapidly rose in the Western world, but prevalence remained relatively low (that is, second epidemiological stage). After each decade of escalating incidence, the prevalence accumulated; this aspect is analogous to compound interest in which interest (that is, incidence) earned over time is added to the principal fund (that is, prevalence) and is more than withdrawals (that is, mortality). In the third epidemiological stage, the 'tug-of-war' between incidence and mortality greatly favours incidence, and so prevalence increases. The Prevalence Doubling Period - the time taken for the prevalence in a defined region to double conceptualizes the magnitude of rising prevalence. In the Western world, the Prevalence Doubling Period is currently likely to be 20-25 years; for example, in Olmsted County, MN, USA, the Prevalence Doubling Period was approximately 25 years from 145 per 100,000 in 1965 to 362 per 100,000 in $1991\left(\mathrm{REFS}^{32,67,68}\right)$. In 2011, the prevalence of IBD was 533 per 100,000 in Olmsted County, and therefore almost doubled again in the 20 years from 1991 (REF. ${ }^{28}$ ). Population-based epidemiological studies from Canada and Scotland published in 2019 documented the Compounding Prevalence of IBD: during the twenty-first century, prevalence rose by $3 \%$ and $4 \%$ per year in Canada and Scotland, respectively ${ }^{9,69}$. In 2008, the calculated prevalence of IBD in Canada and Scotland was $0.51 \%{ }^{70}$ and $0.57 \%{ }^{69}$, respectively, which was similar to the $0.53 \%$ reported in Olmsted County in 2011 (REF. $^{28}$ ). Forecasting models indicate that the prevalence doubling point of $1 \%$ would occur over 22 years in Canada $(2008 \text { to } 2030)^{9}$ and 20 years in Scotland (2008 to 2028$)^{69}$. 
Owing to natural population growth over time, including both new births and projected immigration patterns, the doubling of prevalence from $0.5 \%$ to $1.0 \%$ in some countries/regions, represents a more than $200 \%$ rise in the number of individuals with IBD. For example, in Canada, 0.51\% prevalence of IBD in 2008 represented 169,564 individuals with IBD, whereas 402,853 individuals are predicted to be living with IBD in 2030 - a $238 \%$ increase from 2008. The consistency of reported and forecast data between North America and Europe highlights an impending challenge for health-care providers, administrators and systems. TABLE 1 shows the population of individuals with IBD in selected regions in the Western world with currently high IBD prevalence assuming a growth in prevalence from $0.5 \%$ in 2010 , to $0.75 \%$ in 2020 and to $1 \%$ in 2030 . Accounting for natural population growth and assuming a $1 \%$ prevalence in 2030 , the number of people living with IBD in the Western world over the next decade could surpass ten million - the most people with IBD ever recorded (TABLE 1). Perhaps more concerning than the growth to a $1 \%$ prevalence over the next decade is whether the Western world will experience another doubling of prevalence by 2050 , bringing the IBD population to $2 \%$. Fortunately, it is unlikely that another doubling of prevalence is in store for regions in most of Europe, North America or Oceania; it is far more likely that these regions will transition to the fourth epidemiological stage (Prevalence Equilibrium) before 2050.

\section{Stage four: Prevalence Equilibrium}

Individuals born between 1944 and 1964 are known as the 'baby boomer generation' from the sharp increase in births stemming from the economic prosperity following the end of World War II ${ }^{71}$. In 2030, this generation will be aged $66-84$ years, meaning that nearly one in five people living in the Western world will be over the age of 65 years $^{71}$. Economists highlight the potential fiscal challenge associated with the shifting age demographic as the proportion of older individuals increases relative to those aged 15-64 years (considered here to represent the working-age population $)^{72,73}$. Moreover, life expectancy has increased with advances in public health and innovations in medicine ${ }^{74}$. Consequently, health-care systems face an expanding demographic burden as baby boomers age and life expectancy increases ${ }^{71}$. The IBD population in the Western world will undergo similar shifts in population demographics that will ultimately led to

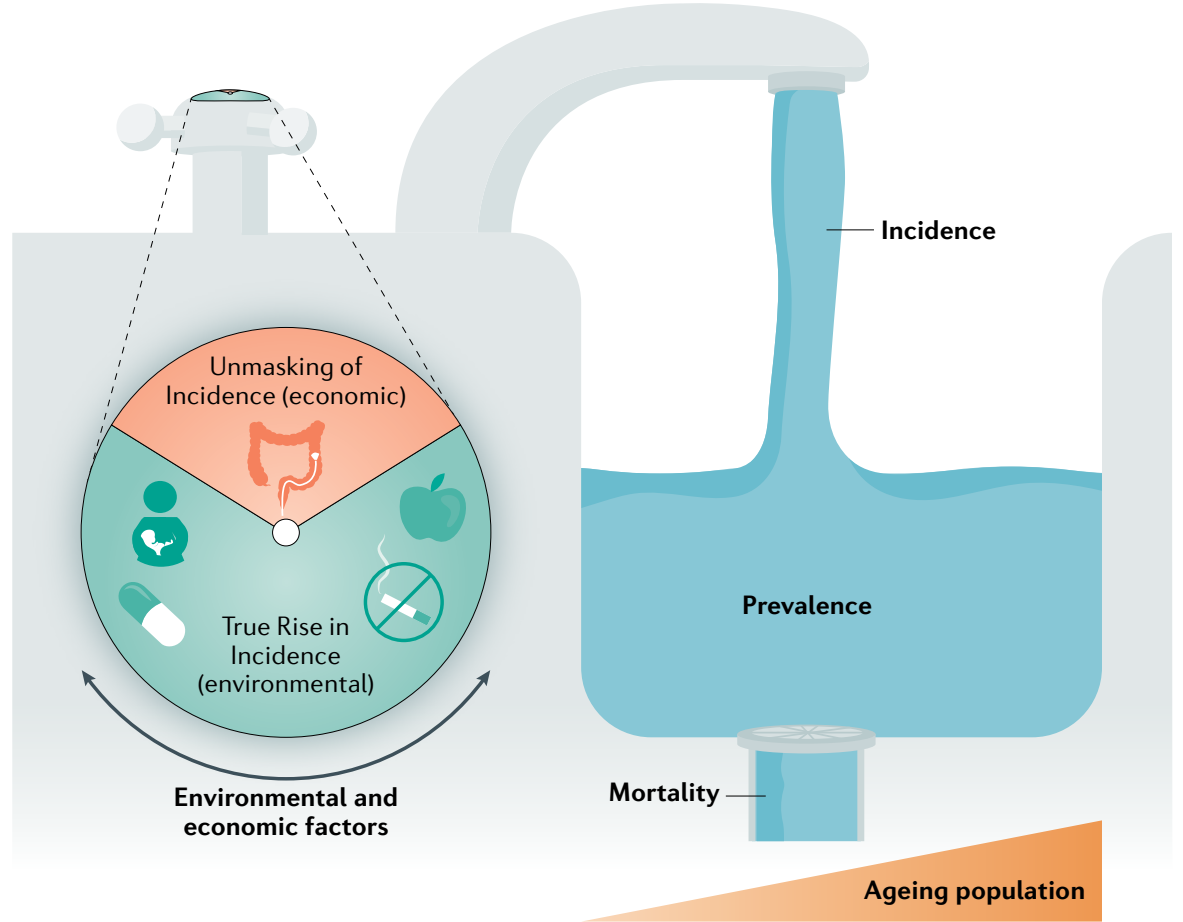

Fig. 3 | The interplay and determinants of IBD incidence, prevalence and mortality. The figure shows the Unmasking of Incidence by economic factors that improve the detection of undiagnosed inflammatory bowel disease (IBD) (for example, access to colonoscopy) and the True Rise in incidence due to westernization of society (for example, smoking) that influence the extent of incidence (water from the tap), which adds to the prevalent population (accumulation of water in the sink). The prevalence level is then affected by the rate of mortality, which is influenced by ageing of the IBD population with complications from longstanding disease, age-related comorbidities and COVID-19.

transition in the epidemiological stages from Compounding Prevalence to the fourth epidemiological stage - Prevalence Equilibrium.

Prevalence Equilibrium is a hypothetical state in which the incidence of IBD approximates the mortality, causing prevalence to stabilize and, in some regions, decline (FIG. 3). The IBD population has aged over time: there are more older individuals with IBD in 2020 than in 1990. For example, the prevalence of IBD among older individuals in Ontario, Canada, increased by $5.2 \%$ per year between 1999 and 2008 (REF. ${ }^{75}$ ). Thus, the likelihood of the 1990 IBD cohort surviving to 2020 was higher than it is for the 2020 IBD cohort surviving to 2050 . The ageing IBD population will have reduced life expectancy from age-related comorbidities such as cardiovascular disease and cancer, as well as a small increased risk of death of patients with IBD as compared with age-matched individuals without IBD as controls ${ }^{63,76}$. Consequently, the prevalence of IBD is unlikely to double to $2 \%$.

Although the Prevalence Equilibrium stage is conjectural, several signs are indicative of its arrival: decline in the slope of prevalence over time; prolongation of the
Prevalence Doubling Period; and an elevated ratio of the prevalence of IBD among older individuals to the prevalence among the working-age population (elderly to working-age ratio; EWAR-IBD). A shift to the fourth epidemiological stage will be preceded by a change in the slope of prevalence over time. A steep slope - positive or negative - is representative of rapid acceleration or deceleration in prevalence, whereas minor fluctuations in a mostly flat slope indicate relative stability (FIG. 1). As the IBD population ages, their mortality increases and, in conjunction with stable (and even more so with declining) incidence, the steep positive slope indicative of Compounding Prevalence will eventually become more moderate until the point where prevalence levels off, and potentially declines thereafter.

As regions begin to transition between Compounding Prevalence to Prevalence Equilibrium, the Prevalence Doubling Period will increase in length. In the Western world, the Prevalence Doubling Period is currently 20-25 years ${ }^{3,4,77}$. Although prevalence is anticipated to increase over the next decade, as regions transition to the fourth stage, the steep slope of prevalence will decline, leading to a lengthening of 
the prevalence doubling time. This second indicator of the Prevalence Equilibrium will be seen in future studies that will document prevalence not rising by an anticipated $50 \%$ within a period of 10-12.5 years. By contrast, newly industrialized countries that are undergoing rapid increases in incidence currently show very short Prevalence Doubling Periods, which extend as the regions get nearer to stage 3 . For example, in Taiwan, IBD prevalence doubled from 4.54 per 100,000 in 2001-2005 to 9.39 per 100,000 in 2006-2010 but was just short of doubling again in 2011-2015, suggesting a roughly 5-year Prevalence Doubling Period $^{78}$. By contrast, in South Korea, which began westernizing earlier, the prevalence of IBD was 57.37 per 100,000 in 2009 , but had not quite doubled to 95.59 per 100,000 in 2016, suggesting a Prevalence Doubling Period closer to 10 years $^{79}$.

The EWAR-IBD represents the relationship between the prevalence of IBD in the population over the age of 64 years and the prevalence in those aged 15-64 years.
The EWAR-IBD is conceptually analogous to the old-age dependency ratio that is used in population demography to estimate the number of individuals older than 65 years for every 100 individuals aged $20-64$ years $^{80}$. Older individuals with IBD are the fastest growing population with IBD in Canada ${ }^{75}$. In Canada, the total (all ages) prevalence of IBD rose from 448 per 100,000 in 2002 to 646 per 100,000 in 2008 to 976 per 100,000 in 2018 (REF. ${ }^{9}$ ). During this period the EWAR-IBD in Canada increased from 0.18 (2002) to 0.22 (2008) to $0.33(2018)^{9}$. An EWAR-IBD of 0.33 in 2018 means that 33 individuals with IBD were older than 64 years for every 100 individuals with IBD aged 15-64 years in Canada. Once the EWAR-IBD exceeds 0.5 (that is, one individual with IBD older than 64 years for every two individuals with IBD aged 15-64 years), then we hypothesize that a region might begin to transition to Prevalence Equilibrium.

So, are regions in the Western world at the threshold of entering the fourth epidemiological stage in 2020 ? No. For

Table 1 | Projected IBD population in selected industrialized countries of the Western world

\begin{tabular}{|c|c|c|c|c|}
\hline \multirow[t]{2}{*}{ Region } & \multicolumn{3}{|c|}{ Prevalent IBD population } & \multirow{2}{*}{$\begin{array}{l}\text { Increase } \\
2010-2030(\%)\end{array}$} \\
\hline & $2010(0.5 \%)$ & $2020(0.75 \%)$ & $2030(1 \%)$ & \\
\hline Australia & 110,158 & 192,060 & 283,930 & 258 \\
\hline Austria & 41,817 & 66,622 & 90,170 & 216 \\
\hline Belgium & 54,477 & 86,535 & 119,040 & 219 \\
\hline Canada & 170,024 & 282,630 & 402,853 & 237 \\
\hline Denmark & 27,738 & 43,800 & 60,470 & 218 \\
\hline Finland & 26,816 & 41,610 & 56,560 & 230 \\
\hline France & 325,137 & 505,822 & 695,090 & 214 \\
\hline Germany & 408,884 & 620,085 & 815,200 & $199^{a}$ \\
\hline Greece & 55,606 & 79,987 & 103,550 & $186^{\mathrm{a}}$ \\
\hline Hungary & 50,000 & 72,712 & 90,920 & $182^{\mathrm{a}}$ \\
\hline Ireland & 22,800 & 36,997 & 52,550 & 230 \\
\hline Italy & 296,387 & 451,875 & 591,960 & 200 \\
\hline Netherlands & 83,077 & 129,975 & 177,390 & 214 \\
\hline New Zealand & 21,753 & 37,282 & 53,420 & 246 \\
\hline Norway & 24,446 & 40,665 & 58,540 & 239 \\
\hline Portugal & 52,865 & 76,462 & 98,320 & $186^{\mathrm{a}}$ \\
\hline Spain & 232,884 & 350,332 & 462,740 & $199^{a}$ \\
\hline Sweden & 46,890 & 77,392 & 109,330 & 233 \\
\hline Switzerland & 39,124 & 64,807 & 91,450 & 234 \\
\hline UK & 313,831 & 504,180 & 702,770 & 224 \\
\hline USA & $1,546,630$ & $2,489,362$ & $3,544,480$ & 229 \\
\hline
\end{tabular}

The prevalence values of $0.5 \%$ in $2010,0.75 \%$ in 2020 and $1 \%$ in 2030 were assumed on the basis of the results of two separate studies in 2019 (one on Canadian ${ }^{9}$ data and one on Scottish ${ }^{69}$ data) that independently predicted that both regions would reach a $1 \%$ prevalent population by 2030 (the Canadian prevalence was $0.51 \%$ in 2008 and $0.75 \%$ in 2020 (REF. $\left.{ }^{9}\right)$, and these predicted prevalence values were applied to other

Western countries for 2010, 2020 and 2030. The projected population values were taken from worldbank.org (accessed 22 January 2020$)^{98}$. ${ }^{2}$ Percentage changes $<200 \%$ are due to a predicted decline in population values for the region over the 2010-2030 period. IBD, inflammatory bowel disease.

example, the incidence of IBD in Alberta, Canada, which has among the highest reported incidence of IBD in the world ${ }^{65}$, fell by $2.6 \%$ per year from 38.3 per 100,000 in 2007 to 28.7 per 100,000 in 2015 ; however, based on mortality of individuals with IBD in 2015, the incidence of IBD has to fall below 8 per 100,000 for prevalence to stabilize ${ }^{65}$. Consequently, individuals with newly diagnosed IBD will continue to add to the prevalent population, which will continue to drive Compounding Prevalence over the next decade, with prevalence forecast to be $1 \%$ by 2030 (REF. ${ }^{9}$ ). The gap between incidence and mortality is so wide that decades will probably pass before countries in the Western world enter Prevalence Equilibrium.

\section{Global IBD epidemiology: 2020 to 2050}

Every region in the world is currently in one of the first three epidemiological stages of IBD evolution and, with time, will transition through all four stages ${ }^{1}$ (FIG. 4). Developing countries are currently in the first stage of evolution (Emergence) and can expect to transition to the second stage if their economies advance and their societies westernize. Most newly industrialized countries are entrenched in the second stage (Acceleration in Incidence), but if these regions follow the epidemiological patterns of the Western world, they are likely to transition into the third stage over the next three decades. The Western world is in the third epidemiological stage (Compounding Prevalence), and is anticipated to cross towards Prevalence Equilibrium within the next 30 years. The clinical challenges are different for each of the epidemiological stages of IBD evolution. Understanding the transition from the current epidemiological stage (in 2020) to the next stage is paramount to prepare for the evolving burden of IBD over the next 30 years in each of these different regions.

Developing countries have a low per capita income, with their economies predominantly driven by agriculture, and are at the earliest stages of industrialization. Health-care infrastructure in these countries is limited, and disease surveillance can be rudimentary. Consequently, observational data on the incidence and prevalence of IBD in these regions are lacking. For example, high-quality population-based epidemiological data from developing countries in Africa are essentially non-existent. However, IBD can, and does, manifest among individuals from developing countries. For example, children of immigrants from sub-Saharan Africa to Canada had a similar risk of IBD 
as children of non-immigrants ${ }^{66}$, and the same was observed among Ethiopian Jewish individuals immigrating to Israel ${ }^{81}$. Moreover, non-population-based studies have shown a rising number of IBD cases in certain areas of developing countries in Africa such as Accra in Ghana ${ }^{82}$ and Khartoum in Sudan ${ }^{83}$. Some challenges for developing countries in the first stage of IBD evolution include: recognition of IBD (that is, differentiating IBD from infectious gastrointestinal disease); appropriate training of clinicians and advances in health-care infrastructure and equipment (such as access to colonoscopy); increased access to specialists; equity of care for poor and rural residents; and adoption of surveillance systems to track cases of IBD $^{2,10}$. Most importantly, developing countries should be aware that, if their economies advance and their societies show greater westernization, the incidence of IBD will rise throughout the twenty-first century. Lessons from newly industrialized countries in Asia and Latin America that transitioned to the second stage at the turn of the twenty-first century can prepare developing countries before they move beyond the Emergence stage. The international IBD community should invest in clinical care and epidemiological surveillance systems of IBD in developing countries - both to support the anticipated rising incidence as seen in the developing world and for the unique opportunity to institute research aimed at exploring the social and environmental determinants of IBD.

Newly industrialized countries in Asia and Latin America that are embedded in the second epidemiological stage are currently (in 2020) experiencing a juxtaposition of rapidly rising incidence with low prevalence. If newly industrialized countries follow the same epidemiological patterns as the Western world, then, over the next 30 years, these countries should approximate the Coalescing Incidence Range for IBD in the Western world: 12-26 per 100,000. Moreover, after several decades of accelerated incidence, prevalence will begin to climb rapidly as these regions enter the Compounding Prevalence stage, similar to the experience in the Western world at the turn of the twenty-first century. For example, Japan and South Korea experienced rapid industrialization after World War II and transitioned into the second stage earlier than other countries in Asia ${ }^{55,84}$. Japan and South Korea serve as examples of the anticipated escalation in prevalence that will manifest throughout Asia over the next 30 years. A nationwide study in Japan demonstrated a prevalence of IBD of 24 per 100,000 in 1991 (REF. ${ }^{85}$ ), which increased to 76 per 100,000 in 2003-2005 $\left(\right.$ REF. $\left.^{86}\right)$ and to 228.5 per 100,000 in 2014 $\left(\mathrm{REF}^{87}\right)$. The increase in prevalence in Japan corresponds to 29,700 patients with IBD in 1991 climbing to 290,400 in 2014 (REF. ${ }^{87}$ ). Similarly, the prevalence of IBD in South Korea was 42 per 100,000 in $2005\left(\right.$ REF. $^{88}$ ), 63.8 per 100,000 in 2010 and 92.8 per 100,000 in $2015\left(\right.$ REF $\left.^{79}\right)$. If the prevalence of IBD follows a similar trend in regions such as India and China with populations of more than one billion people ${ }^{57,89}$, Asia alone might have more cases of IBD than the Western world before 2050 (REF. ${ }^{1}$ ). The prevalent IBD population in newly industrialized countries of Asia and Latin America have a younger age demographic as compared with the ageing IBD population of the Western world ${ }^{49}$. Today, in 2020, newly industrialized countries echo the Western world from generations ago when physicians predominantly cared for adolescents and young adults with IBD. Thus, over the next

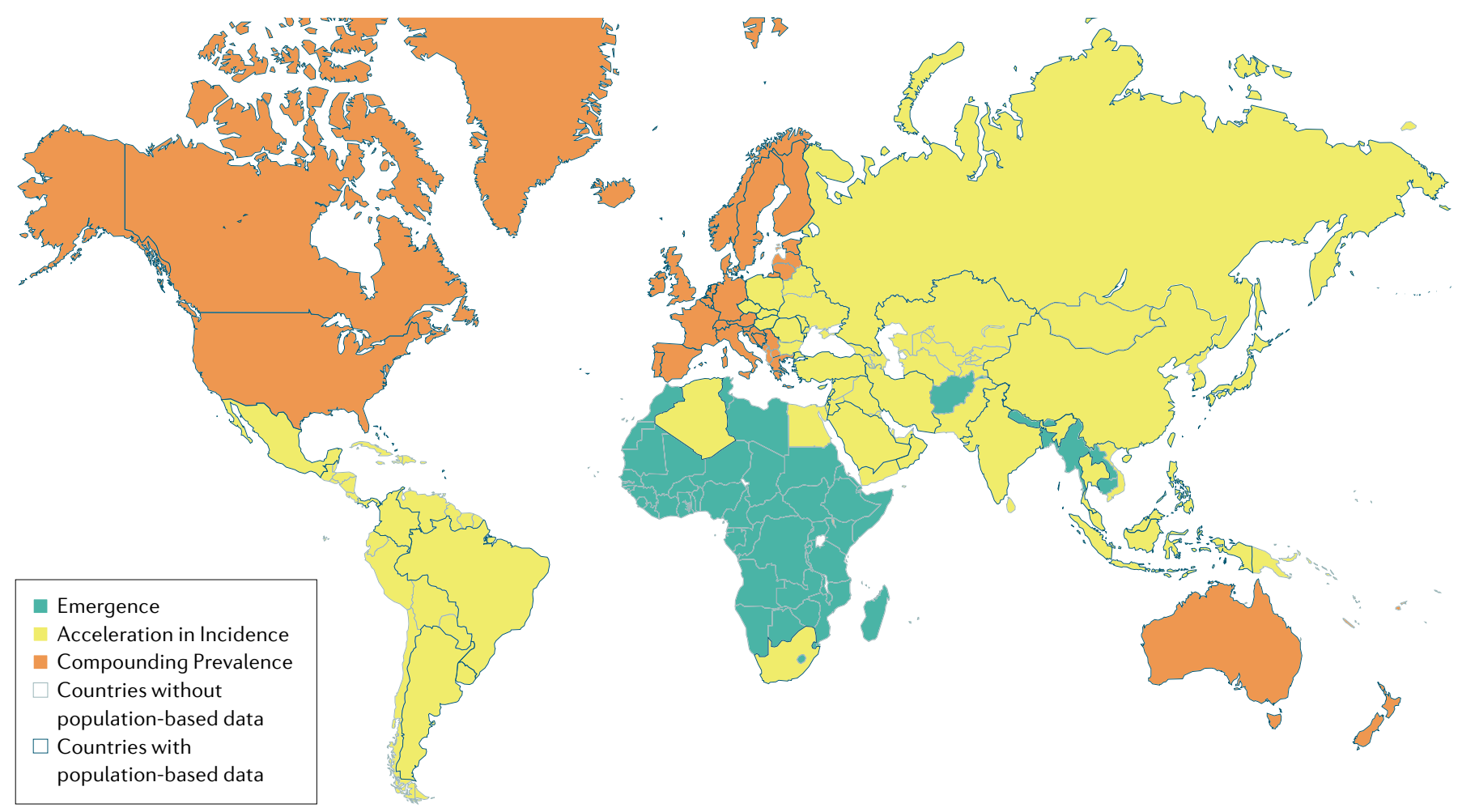

Fig. 4 | Global map of the epidemiological stages of IBD evolution in 2020. Regions are organized into anticipated current epidemiological stage of inflammatory bowel disease (IBD) evolution according to United Nations development classifications (2020) ${ }^{98}$. Regions in the first stage (Emergence) are highlighted in green, regions in the second stage (Acceleration in Incidence) are highlighted in yellow and regions in the third stage (Compounding Prevalence) are highlighted in orange. Regions with black borders are regions for which population-based incidence or prevalence studies are available. Regions with grey borders lack data on incidence or prevalence, highlighting current gaps in knowledge of IBD epidemiology $y^{3,4}$. 


\section{Box 2 | Key points and outlook}

- The evolution of inflammatory bowel disease (IBD) occurs across four epidemiological stages: Emergence, Acceleration in Incidence, Compounding Prevalence and Prevalence Equilibrium.

- In 2020, newly industrialized countries/regions in Asia and Latin America are in the Acceleration in Incidence stage, which is associated with rapidly rising incidence and low prevalence.

- Acceleration in Incidence is driven by the Unmasking of Incidence, in which economic advance improves detection of IBD, and the True Rise of Incidence occurs owing to westernization of society.

- The Western world is in the Compounding Prevalence stage: stable incidence (Coalescing Incidence Range of $12-26$ per 100,000 persons) and rapidly increasing prevalence, which will be as high as $1 \%$ by 2030 in many regions.

- The Western world will transition to Prevalence Equilibrium stage (stabilization of prevalence) owing to the advancing age of the IBD population as denoted by the ratio of the prevalence among older individuals (aged $>64$ years) to the prevalence among the working-age population (aged 15-64 years).

- Shortening the transition to Prevalence Equilibrium via measures for IBD prevention and innovating health-care delivery to address changing demographics of the IBD population might help stem the global IBD burden.

30 years - as newly industrialized countries transition from the second to the third stage - these countries can draw from the lessons learned from the Western world over the past 30 years. Newly industrialized countries will soon need to contend with the adoption and implementation of clinical care paradigms established by the Western world, but modified for local needs. Owing to the tremendous heterogeneity of socioeconomic status between newly industrialized countries, and within disparate regions within any given region, the major challenge will be the equitable, affordable and accessible distribution of care for patients with IBD. Consequently, health-care systems will need to prepare personnel, resources and medical infrastructure in readiness for the global increase in the number of cases of IBD.

Compounding Prevalence in the Western world, in conjunction with an ageing IBD population, will change the face of gastroenterology clinics in the near future. Over the next decade, gastroenterologists involved in adult care will contend with an escalation in the number of patients living with IBD while simultaneously managing an ageing population that will have a mixture of complications of longstanding IBD and age-related comorbidities. Older individuals with IBD will continue to make up a higher proportion of the adult patients attending gastroenterology clinics (that is, with EWAR-IBD exceeding 0.5) and octogenarians with IBD will become more common. Addressing these future clinical pressures will require innovation to health-care delivery in gastroenterology clinics. Potential innovations in delivery of care are multifaceted, but include advances in multidisciplinary care model $\mathrm{s}^{90}$, personalized medicine ${ }^{91}$, telehealth ${ }^{92}$, data mining and electronic medical records ${ }^{93}$, and artificial intelligence used to improve monitoring and treatment of $\operatorname{IBD}^{94,95}$.

In parallel with innovating health-care delivery, the IBD community should focus on efforts to shorten the transition time from Compounding Prevalence to Prevalence Equilibrium. Expediting this transition will facilitate health-care system stability as the number of cases will be relatively stable year to year, enabling easier and/or better resource planning by health-care administrators and policy-makers. Moreover, Prevalence Equilibrium might result in a decline in prevalence in certain jurisdictions, which would reduce the overall burden of IBD to society. A concerted focus on the prevention of IBD could drive the decline in IBD incidence. New research on the gut microbiome and environmental determinants that focus on IBD disease prevention are ultimately needed to decelerate the slope of the increasing prevalence of IBD across the world. Among Western countries/regions where incidence is reported to be decreasing, the causes for the declining incidence should be explored and proven environmental modification strategies should be adopted in other regions ${ }^{10}$.

Finally, unexpected events could entirely change the evolution of the global epidemiology of IBD. A fundamental discovery that leads to a cure for IBD would dramatically decrease its incidence. Alternatively, the ongoing COVID-19 global pandemic has the potential to dramatically affect mortality among the prevalent IBD population ${ }^{96}$. Surveillance Epidemiology of Coronavirus Under Research Exclusion (SECURE-IBD) is an international registry reporting on patients with IBD who have tested positive for COVID-19. An interactive updated online map of the SECURE-IBD registry can be found in Related links. The primary risk factor for a severe complication of COVID-19 - defined as ventilator use, intensive care unit admission or death - in patients with IBD is advanced age. Among people over the age of 60 years who were reported in SECURE-IBD, 20\% experienced a severe complication of COVID-19, with older age (adjusted OR $1.04,95 \%$ CI 1.01-1.06) and two or more comorbidities (adjusted OR 2.9, 95\% CI 1.1-1.78) associated with poor outcomes. Consequently, older people are the most vulnerable population with IBD during the pandemic ${ }^{97}$. This tragic, unprecedented pandemic could contribute to an earlier transition to Prevalence Equilibrium.

\section{Conclusions}

IBD serves as a case study on the evolution of modern diseases. This Perspective provides a novel framework for describing the changing epidemiological patterns of IBD globally: from the industrial revolution, to the current state in 2020, and projected out to 2050 (BOX 2). Additionally, this article synthesizes terminology and introduces new definitions that explain the evolution of IBD across epidemiological transition periods (BOX 1). The four epidemiological stages of IBD are Emergence, Acceleration in Incidence, Compounding Prevalence and Prevalence Equilibrium.

The global burden of IBD can be mitigated by shortening the transition from Compounding Prevalence to Prevalence Equilibrium. To accomplish this goal, the IBD community should focus on disease prevention to drive down the incidence of IBD. In the meantime, developing, newly industrialized regions and countries of the Western world all need to innovate their current health-care delivery to address the evolving demographics of their IBD populations as they transition across epidemiological stages.

Gilaad G. Kaplan (D) ${ }^{1,2}$ and Joseph W. Windsor (iD) $^{1,2}$

${ }^{\prime}$ Department of Medicine, University of Calgary, Calgary, Alberta, Canada.

${ }^{2}$ Department of Community Health Sciences, University of Calgary, Calgary, Alberta, Canada.

凶e-mail: ggkaplan@ucalgary.ca https://doi.org/10.1038/s41575-020-00360-x

\section{Published online 8 October 2020}

1. Kaplan, G. G. The global burden of IBD: from 2015 to 2025. Nat. Rev. Gastroenterol. Hepatol. 12, 720-727 (2015).

2. Kaplan, G. G. \& Ng, S. C. Globalisation of inflammatory bowel disease: perspectives from the evolution of inflammatory bowel disease in the UK and China. Lancet Gastroenterol. Hepatol. 1, 307-316 (2016)

3. Molodecky, N. A. et al. Increasing incidence and prevalence of the inflammatory bowel diseases with 
time, based on systematic review. Gastroenterology 142, 46-54 (2012).

4. $\mathrm{Ng}, \mathrm{S}$. C. et al. Worldwide incidence and prevalence of inflammatory bowel disease in the 21 st century: a systematic review of population-based studies. Lancet 390, 2769-2778 (2018).

5. Omran, A. R. The epidemiologic transition. A theory of the epidemiology of population change. Milbank Mem Fund. Q. 49, 509-538 (1971).

6. Barrett, B., Charles, J. W. \& Temte, J. L. Climate change, human health, and epidemiological transition. Prev. Med. 70, 69-75 (2015).

7. Zuckerman, M. K., Harper, K. N., Barrett, R. \& Armelagos, G. J. The evolution of disease: anthropological perspectives on epidemiologic transitions. Glob. Health Action. 7, 23303 (2014).

8. Kedia, S. \& Ahuja, V. Is the emergence of inflammatory bowel disease a prime example of "the third epidemiological transition"? Indian J. Gastroenterol. 37, 183-185 (2018)

9. Coward, S. et al. Past and future burden of inflammatory bowel diseases based on modeling of population-based data. Gastroenterology 156, 1345-1353 (2019).

10. Kaplan, G. G. \& Ng, S. C. Understanding and preventing the global increase of inflammatory bowel disease. Gastroenterology 152, 313-321 (2017).

11. Darwin, C. On the Origin of Species by Means of Natural Selection, or the Preservation of Favoured Races in the Struggle for Life (J. Murray, 1859).

12. Orrego, F. \& Quintana, C. Darwin's illness: a final diagnosis. Notes Rec. R. Soc. Lond. 61, 23-29 (2007).

13. Baillie, M. The Morbid Anatomy of Some of the Most Important Parts of the Human Body (J. Johnson, 1793).

14. Abercrombie, J. Pathological and Practical Researches on Diseases of the Stomach, the Intestina Canal, the Liver and other Viscera of the Abdomen (Carey \& Lea, 1828).

15. Wilks, S. Morbid appearances in the intestine of Miss Bankes. Lond. Med. Gazette 2, 264 (1859).

16. White, H. A discussion on "ulcerative colitis." Introductory address. Proc. R. Soc. Med. 2, 79-82 (1909).

17. Mulder, D. J., Noble, A. J., Justinich, C. J. \& Duffin, J. M. A tale of two diseases: the history of inflammatory bowel disease. J. Crohns Colitis 8, 341-348 (2014).

18. Allchin, W. H. A discussion on "ulcerative colitis": introductory address. Proc. R. Soc. Med. 2, 59-75 (1909).

19. Dalziel, T. K. Chronic interstitial enteritis. Br. Med. J. 2, 1068-1070 (1913)

20. Crohn, B. B., Ginzburg, L. \& Oppenheimer, G. D. Regional ileitis: a pathologic and clinical entity. J. Am. Med. Assoc. 99, 1323-1329 (1932)

21. Chopra, R. N. \& Ray, P. N. Chronic ulcerative colitis. Ind. Med. Gaz. 74, 65-74 (1939).

22. Jiang, X. L. \& Cui, H. F. An analysis of 10218 ulcerative colitis cases in China. World J. Gastroenterol. 8 158-161 (2002).

23. Crutzen, P. J. \& Stoermer, E. F. Anthropocene. IGBP Glob. Change Newslet. 41, 17-18 (2000).

24. Waters, C. N. et al. The Anthropocene is functionally and stratigraphically distinct from the Holocene. Science 351, aad2622 (2016).

25. Steffen, W., Broadgate, W., Deutsch, L., Gaffney, O. \& Ludwig, C. The trajectory of the Anthropocene: the Great Acceleration. Anthr. Rev. 2, 81-98 (2015).

26. Roser M., Ritchie H. \& Ortiz-Ospina E. World Population Growth. https://ourworldindata.org/worldpopulation-growth (2019).

27. Steffen, W., Crutzen, J. \& McNeill, J. R. The Anthropocene: are humans now overwhelming the great forces of Nature? Ambio 36, 614-621 (2007).

28. Shivashankar, R., Tremaine, W. J., Harmsen, W. S. $\&$ Loftus, E. V. Jr. Incidence and prevalence of Crohn's disease and ulcerative colitis in Olmsted county, Minnesota from 1970 through 2010. Clin. Gastroenterol. Hepatol. 15, 857-863 (2017)

29. Gunesh, S., Thomas, G. A., Williams, G. T., Roberts, A. $£$ Hawthorne, A. B. The incidence of Crohn's disease in Cardiff over the last 75 years: an update for 1996-2005. Aliment. Pharmacol. Ther. 27, 211-219 (2008).

30. Mayberry, J., Rhodes, J. \& Hughes, L. E. Incidence of Crohn's disease in Cardiff between 1934-1977. Gut 20, 602-608 (1979).

31. Rose, J. D., Roberts, G. M., Williams, G., Mayberry, J. F. \& Rhodes, J. Cardiff Crohn's disease jubilee: the incidence over 50 years. Gut 29, 346-351 (1988).

32. Loftus, E. V. Jr. et al. Ulcerative colitis in Olmsted County, Minnesota, 1940-1993: incidence, prevalence, and survival. Gut 46, 336-343 (2000).
33. Jacobsen, B. A. et al. Increase in incidence and prevalence of inflammatory bowel disease in northern Denmark: a population-based study, 1978-2002. Eur. J. Gastroenterol. Hepatol. 18, 601-606 (2006).

34. Björnsson, S. Inflammatory bowel disease in Iceland during a 30-year period, 1950-1979. Scand. J. Gastroenterol. Suppl. 170, 47-79 (1989).

35. Lakatos, L. et al. Striking elevation in incidence and prevalence of inflammatory bowel disease in a province of western Hungary between 1977-2001. World J. Gastroenterol. 10, 404-409 (2004).

36. Kaplan, G. G. et al. The impact of inflammatory bowel disease in Canada 2018: epidemiology. J. Can. Assoc. Gastroenterol. 2, S6-S16 (2019).

37. Benchimol, E. I. et al. Changing age demographics of inflammatory bowel disease in Ontario, Canada: a population-based cohort study of epidemiology trends. Inflamm. Bowel Dis. 20, 1761-1769 (2014).

38. Roberts S. E. et al. A systematic review and meta analysis of paediatric inflammatory bowel disease incidence and prevalence across Europe. J. Crohns Colitis https://doi.org/10.1093/ecco-jcc/jjaa037 (2020).

39. Benchimol, E. I. et al. Incidence, outcomes, and health services burden of very early onset inflammatory bowel disease. Gastroenterology 147, 803-813 (2014).

40. Su, H. Y., Gupta, V., Day, A. S. \& Gearry, R. B. Rising incidence of inflammatory bowel disease in Canterbury, New Zealand. Inflamm. Bowel Dis. 22, 2238-2244 (2016).

41. Chaaro Benallal D et al. Evolution of the incidence of inflammatory bowel disease in Southern Spain. Rev. Esp. Enferm. Dig. 109, 757-760 (2017).

42. Lophaven, S. N., Lynge, E. \& Burisch, J. The incidence of inflammatory bowel disease in Denmark 1980-2013: a nationwide cohort study. Aliment. Pharmacol. Ther 45, 961-972 (2017).

43. Leddin, D., Tamim, H. \& Levy, A. R. Decreasing incidence of inflammatory bowel disease in eastern Canada: a population database study. $B M C$ Gastroenterol. 14, 140 (2014).

44. Hammer, T., Nielsen, K. R., Munkholm, P., Burisch, J. $\&$ Lynge, E. The Faroese IBD study: incidence of inflammatory bowel diseases across 54 years of population-based data. J. Crohns Colitis. 10 , 934-942 (2016).

45. Molodecky, N. A. et al. Challenges associated with identifying the environmental determinants of the inflammatory bowel diseases. Inflamm. Bowel Dis. 17 1792-1799 (2011).

46. Hammer, T. et al. Dietary risk factors for inflammatory bowel diseases in a high-risk population: results from the Faroese IBD study. U. Eur. Gastroenterol. J. 7, 924-932 (2019)

47. Abdulla, M. et al. Inflammatory bowel disease in Bahrain: single-center experience. Clin. Exp. Gastroenterol. 10, 133-145 (2017).

48. Mokhtar, N. M. et al. A four-decade analysis of the incidence trends, sociodemographic and clinical characteristics of inflammatory bowel disease patients at single tertiary centre, Kuala Lumpur, Malaysia. BMC Public Health 19, 550 (2019).

49. Kotze, P. G. et al. Progression of inflammatory bowe diseases throughout Latin America and the Caribbean: a systematic review. Clin. Gastroenterol. Hepatol. 18 , 304-312 (2020).

50. Victoria, C. R., Sassak, L. Y. \& Nunes, H. R. Incidence and prevalence rates of inflammatory bowel diseases, in midwestern of Sao Paulo State, Brazil. Arq. Gastroenterol. 46, 20-25 (2009).

51. Gasparini, R. G., Sassaki, L. Y. \& Saad-Hossne, R. Inflammatory bowel disease epidemiology in Sao Paulo State, Brazil. Clin. Exp. Gastroenterol. 11 423-429 (2018)

52. $\mathrm{Ng}, \mathrm{S}$. C. et al. Incidence and phenotype of inflammatory bowel disease based on results from the Asia-Pacific Crohn's and colitis epidemiology study. Gastroenterology 145, 158-165 (2013).

53. Ng, S. C. et al. Population density and risk of inflammatory bowel disease: a prospective populationbased study in 13 countries or regions in Asia-Pacific. Am. J. Gastroenterol. 114, 107-115 (2019).

54. Ananthakrishnan, A. N. Epidemiology and risk factors for IBD. Nat. Rev. Gastroenterol. Hepatol. 12, 205-217 (2015)

55. Mak, W. Y., Zhao, M., Ng, S. C. \& Burisch, J. The epidemiology of inflammatory bowel disease: East meets west. J. Gastroenterol. Hepatol. 35, 380-389 (2020)

56. Ng, S. C. et al. Environmental risk factors in inflammatory bowel disease: a population-based case-control study in Asia-Pacific. Gut 64, 1063-1071 (2015).

57. Kedia, S. \& Ahuja, V. Epidemiology of inflammatory bowel disease in India: the great shift east. Inflamm Intest. Dis. 2, 102-115 (2017).

58. Freeman, J. \& Hutchison, G. B. Prevalence, incidence and duration. Am. J. Epidemiol. 112, 707-723 (1980).

59. Feenstra, T. L., van Genugten, M. L., Hoogenveen, R. T., Wouters, E. F. \& Rutten-van Mölken, M. P. The impact of aging and smoking on the future burden of chronic obstructive pulmonary disease: a model analysis in the Netherlands. Am. J. Respir. Crit. Care Med. 164, 590-596 (2001)

60. Brookmeyer, R. \& Gray, S. Methods for projecting the incidence and prevalence of chronic diseases in aging populations: application to Alzheimer's disease. Stat. Med. 19, 1481-1493 (2000).

61. Etzioni, R., Cha, R., Feuer, E. J. \& Davidov, O. Asymptomatic incidence and duration of prostate cancer. Am. J. Epidemiol. 148, 775-785 (1998).

62. Gail, M. H., Kessler, L., Midthune, D. \& Scoppa, S. Two approaches for estimating disease prevalence from population-based registries of incidence and total mortality. Biometrics 55, 1137-1144 (1999).

63. Bitton, A., Vutcovici, M., Sewitch, M., Suissa, S. \& Brassard, P. Mortality trends in Crohn's disease and ulcerative colitis: a population-based study in Quebec, Canada. Inflamm. Bowel Dis. 22, 416-423 (2016).

64. Burisch, J. et al. East-West gradient in the incidence of inflammatory bowel disease in Europe: the ECCO-EpiCom inception cohort. Gut 63, 588-597 (2014).

65. Coward, S. et al. The evolving incidence of inflammatory bowel disease: what will the future hold? J. Can. Assoc. Gastroenterol. 2, 56-58 (2019).

66. Benchimol, E. I. et al. Inflammatory bowel disease in immigrants to Canada and their children: a populationbased cohort study. Am. J. Gastroenterol. 110 553-563 (2015).

67. Sedlack, R. E., Nobrega, F. T., Kurland, L. T. \& Sauer, W. G. Inflammatory colon disease in Rochester Minnesota, 1935-1964. Gastroenterology 62, 935-941 (1972)

68. Loftus, E. V. Jr. et al. Crohn's disease in Olmsted County, Minnesota, 1940-1993: incidence, prevalence, and survival. Gastroenterology 114 1161-1168 (1998).

69. Jones, G. R. et al. IBD prevalence in Lothian, Scotland derived by capture-recapture methodology. Gut 68 , 1953-1960 (2019).

70. Coward S. Forecasting the Future: A Trek through the Changing Landscape of Inflammatory Bowel Disease. Thesis, Univ. Calgary (2019)

71. Knickman, J. R. \& Snell, E. K. The 2030 problem: caring for aging baby boomers. Health Serv. Res. 37, 849-884 (2002).

72. Muszynska, M. M. \& Rau, R. The old-age healthy dependency ratio in Europe. J. Popul. Ageing 5 151-162 (2012)

73. Sanderson, W. C. \& Scherbov, S. Average remaining lifetimes can increase as human populations age. Nature 435, 811-813 (2005).

74. Appleby, J. How long can we expect to live? BMJ 346 f331 (2013)

75. Nguyen, G. C. et al. The impact of inflammatory bowel disease in Canada 2018: IBD in seniors. J. Can. Assoc. Gastroenterol. 2, S68-S72 (2019).

76. Bernstein, C. N., Nugent, Z., Targownik, L. E. Singh, H. \& Lix, L. M. Predictors and risks for death in a population-based study of persons with IBD in Manitoba. Gut 64, 1403-1411 (2015).

77. Windsor, J. W. et al. Parallel epidemiologies in newly vs. highly industrialized countries. J. Can. Assoc. Gastroenterol. 3, 34-35 (2020)

78. Yen, H. H. et al. Epidemiological trend in inflammatory bowel disease in Taiwan from 2001 to 2015: a nationwide populationbased study. Intest. Res. 17 54-62 (2019)

79. Kwak, M. S. et al. Emerging trends of inflammatory bowel disease in South Korea: a nationwide population-based study. J. Gastroenterol. Hepatol. 34, 1018-1026 (2019).

80. Organisation for Economic Co-operation and Development (2017) Pensions at a Glance 2017: OECD and G2O Indicators 122-123 (OECD, 2017).

81. Bar-Gil Shitrit, A et al. Inflammatory bowel disease: an emergent disease among Ethiopian Jews migrating to Israel. Inflamm. Bowel Dis. 21, 631-635 (2015).

82. Archampong, T. N. \& Nkrumah, K. N. Inflammatory bowel disease in Accra: what new trends. West. Afr. J. Med. 32, 40-44 (2013). 


\section{PERSPECTIVES}

83. Khalifa, S. E., Mudawi, H. M. \& Fedail, S. S. Presentation and management outcome of inflammatory bowel disease in Sudan. Trop. Gastroenterol. 26, 194-196 (2005).

84. Ng, W. K., Wong, S. H. \& Ng, S. C. Changing epidemiological trends of inflammatory bowel disease in Asia. Intest. Res. 14, 111-119 (2016).

85. Morita, N. et al. Incidence and prevalence of inflammatory bowel disease in Japan: nationwide epidemiological survey during the year 1991 J. Gastroenterol. 30 (Suppl. 8), 1-4 (1995).

86. Asakura, K. et al. Prevalence of ulcerative colitis and Crohn's disease in Japan. J. Gastroenterol. 44, 659-665 (2009)

87. Murakami, Y. et al. Estimated prevalence of ulcerative colitis and Crohn's disease in Japan in 2014: an analysis of a nationwide survey. J. Gastroenterol. 54 1070-1077 (2019).

88. Yang, S. K. et al. Epidemiology of inflammatory bowel disease in the Songpa-Kangdong district, Seoul, Korea, 1986-2005: a KASID study. Inflamm. Bowel Dis. 14 542-549 (2008)

89. Ye, L., Cao, Q. \& Cheng, J. Review of inflammatory bowel disease in China. ScientificWorldJournal 2013 , 296470 (2013).

90. Regueiro, M. et al. Reduced unplanned care and disease activity and increased quality of life after patient enrollment in an inflammatory bowel disease medical home. Clin. Gastroenterol. Hepatol. 16 1777-1785 (2018)

91. Flamant, M. \& Roblin, X. Inflammatory bowe disease: towards a personalized medicine. Ther. Adv. Gastroenterol. 11, 1756283X17745029 (2018).
92. Cross, R. K. et al. A randomized controlled trial of TELEmedicine for patients with inflammatory bowe disease (TELE-IBD). Am. J. Gastroenterol. 114 472-482 (2019)

93. Ananthakrishnan, A. N. et al. Use of narrative concepts in electronic health records to validate associations between genetic factors and response to treatment of inflammatory bowel diseases. Clin. Gastroenterol. Hepatol. 18, 1890-1892 (2020).

94. Stidham, R. W. et al. Performance of a deep learning model vs human reviewers in grading endoscopic disease severity of patients with ulcerative colitis. JAMA Netw. Open 2, e193963 (2019).

95. Waljee, A. K. et al. Development and validation of machine learning models in prediction of remission in patients with moderate to severe Crohn disease. JAMA Netw. Open 2, e193721 (2019).

96. Wu, F. et al. A new coronavirus associated with human respiratory disease in China. Nature 579, 265-269 (2020).

97. Brenner, E. J et al Corticosteroids, but not TNF antagonists, are associated with adverse COVID-19 outcomes in patients with inflammatory bowel diseases: results from an international registry. Gastroenterology 159, 481-491 (2020).

98. World Bank. Health Nutrition and Population Statistics. https://databank.worldbank.org/source/ health-nutrition-and-population-statistics (2020)

99. United Nations. United Nations World Economic Situation and Prospects. https://www.un.org/ development/desa/dpad/wp-content/uploads/sites/45/ WESP2019_BOOK-web.pdf (2019).

\section{Acknowledgements}

The authors thank F. Underwood and S. Coward for contributing to the article through literature searches, providing advice and graphic design. The authors have received funding from the Canadian Institutes for Health Research Operating Grant reference number PJT 162393.

Author contributions

The authors contributed equally to all aspects of the article.

Competing interests

The authors declare no competing interests.

Peer review information

Nature Reviews Gastroenterology \& Hepatology thanks

V. Ahuja, J. Burisch and M. Kappelman for their contribution to the peer review of this work.

\section{Publisher's note}

Springer Nature remains neutral with regard to jurisdictional claims in published maps and institutional affiliations.

\section{RELATED LINKS}

Global IBD Visualization of Epidemiology Studies: https:// wpsites.ucalgary.ca/gilkaplan/ioibd-gives/

Kaplan Lab interactive maps: https://wpsites.ucalgary.ca/ gilkaplan/

SECURE-IBD interactive map: https://wpsites.ucalgary.ca/ gilkaplan/secure-ibd/

Video Abstract: https://youtu.be/6Cp7TAcc8XM

(C) Springer Nature Limited 2020 